\title{
The Impact of Unemployment on Young People in the Jordanian Community: A Case Study from Unemployed Perspective
}

\author{
Mohammad. M. Hussainat ${ }^{1}$, Qasem. M. Ghnimat ${ }^{2} \&$ Marwan Atef rabee Al - dlaeen ${ }^{3}$ \\ ${ }^{1}$ Department of Social Sciences, Ajloun University Collage, Al Balqa' Applied University, Ajloun, Jordan \\ ${ }^{2}$ Department of Basic Sciences, Al Huson University Collage, Al Balqa' Applied University, Irbid, Jordan \\ ${ }^{3}$ Department of Educational and Social Sciences, Al Karak University College, Al Balqa' Applied University, Al \\ Karak, Jordan \\ Correspondence: Qasem. M. Ghnimat, Department of Basic Sciences, Al Huson University Collage, Al Balqa, \\ Applied University, Irbid, Jordan. Tel: 962-77-206-5165. E-mail: qasem_72@yahoo.com
}

Received: October 4, 2012 Accepted: November 1, 2012 Online Published: December 31, 2012

doi:10.5539/ass.v9n1p155 URL: http://dx.doi.org/10.5539/ass.v9n1p155

\begin{abstract}
The study aimed at identifying the social and psychological effects resulted from unemployment on the youth in the Jordanian community from their own perspective and their future attitudes. In addition it aimed to identify the social roles of the youth which are affected by the different problems they are exposed to because of lack of chances of work which made them anxious, depressed and fear of doing any specific work and being unable to change their life track to the best The objectives of the study were achieved through the instrument of the study which was distributed on the sample of the study. It consisted of (50) unemployed persons. The effects of the unemployment were studied in different areas represented such effects on the social life and the psychological problems of the youth, in addition to such effects on the roles of the youth in the community the findings related to the effect of the unemployment on the social problem that face the youth indicated that the delay of marriage age is the most prominent social problem. As for the psychological problems, the findings showed that the hostility feeling is the worst feeling those persons have within their community especially when comparing themselves with those who work. Finally, as for the roles of the youth, the participants showed that the unemployment causes confusion and disability of doing their own roles in the future. There were no statistically significant differences attributed to the demographic variables on the answers of the participants in all domains of the study Keywords: unemployment, youth, social problems, unemployment and the youth.
\end{abstract}

Keywords: people, young people, unemployed perspective, Jordanian community, Jordan

\section{Introduction}

Unemployment today is considered as one of the most important economic and social issues in any country. This phenomenon is increasing in the developing countries, whereas, there are 16 million unemployed young men in Arab communities according to Davos economic conference. It is expected that the number goes up to 80 million Arab youth in 2013. (www.arabia-edition .blogspot.com)

The main reason for unemployment is due to the increasing pressure on the productive and service sectors in such countries, in addition to the huge negative effect of unemployment on social and economic level. The increasing of unemployment leads to great damages and serious situations wherever an individual can't find a living to meet his basic needs this will drive him causing harm for himself and to others in his community. Additionally, unemployment assassins the dreams of the youth and blocks up their future horizons.

Generally speaking, the Arab countries face a moving rapidly problem taking away the future of University graduates and overwhelming the whole Arab world people having an academic Degrees is the dream of each young person to involve in the real work to contribute in the community establishment to build up the civilization. Effectively; in addition to achieve one's identity un life to gain a high and better rank.

Young men spend their schooling working hard to graduate to find themselves wandering in streets and cafes waiting for any chance for work, which might not be available lees than a year Emptiness could drive them wildly to find themselves in false tracks to be convicted by the evidence of the facts in their community. In addition to the fact that poverty, running after false dreams and hawing psychological setbacks and the burden is 
cast upon him greater than he can bear all can lead sometimes to committing suicide because of being failure and of having no importance in their communities, this condition being the risk of his own life which can oblige most of them to immigrate to look for a job abroad.

\subsection{Problem of the Study}

During the last three decades the Unemployment has become a crucial problem affecting all counties reliability, and it is undoable, a problem which present in any society. In spite of achieving flourishing growth in economy, the crisis of unemployment increases year after year. Having a lack of economic thought and not being able to absorb the unemployment problem and not find the way out enlarging and increasing the seriousness of unemployment .There is a new current of thinking spreading widely implies that the unemployment is the problem of the victims who failed to adapt with the competition and globalization .Therefore, many countries in this world study and analyze the reasons and result of unemployment in its communities constantly, trying to identify the number of unemployed and their percentage according to work power and the total number of population .Unemployment also has became the main concern of politicians and decision makers these days .Those concern with putting plans and programs to decrease the percentage of unemployment in their communities.

The effect of employment is related to political structure, social security, economic development and health issues on the individuals and establishments of the community, make the unemployment problem for all a big concern those who are in charge to increase the educational and crafts level for the manpower which eventually decrease the unemployment and crime, as well (Cantor \& Land 1985).

\subsection{Questions of the Study}

To achieve the purpose of the study, the following questions are to be answered.

1) Is there any effect for unemployment on the youth?

2) What is the impact of unemployment on the social problems the youth face?

3) What is the impact of unemployment on the psychological problems they face?

4) What is the impact of unemployment on the role of the youth in the community?

5) Is there an effect of statistically significant on the demographic variables (sex, age ) from the perspective of the sample of the study in relation with the domains of the study?

\section{Operational definitions}

Unemployed: The individual who gets no work within four weeks of searching for a job and who is capable of work.

Unemployment: The most serious problem that threatens the stability of nations and countries. Its seriousness is not the same in different communities. Unemployment is the main reason for most social diseases that threatens political stability "not having a living".

\subsection{Significance of the Study}

Facing the problem of unemployment demands having future programs and plans but this will be useless unless there is clear scientific understanding for the unemployment and its size. The importance of this study comes from the deep relation and great effect of unemployment with the social structure which is represented in: security, social, health and economic aspects. Basically this importance is embodied through the information any embodied included in the theoretical background of the study which refers to the high level of crime in Saudi Arabia in particular breaking into others properties. which goes side by side with unemployment.

\subsection{Limitations of the Study}

The study is limited by the following:

1) Time: The study has been conducted in the academic year 2012/2013.

2) Place: The study is restricted by a sample consisted of (50) individuals form Ajloun Governorate in Jordan. The results are restricted only by this sample.

3) The findings of the study are identified by the instrument of the study and its validity and reliability.

\section{Theoretical Background and Related Studies}

\subsection{Definition of Unemployment}

In language, unemployment is the deletion of something - something lost (Almu'jam Alwaseed, 1960) It is also 
laziness, Neglecting, missing, losing (Obeid, 1997) Unemployment in law is the unavailability of job opportunities for able and desired people for work (Al Rum main, 1999). It is the stale in which one is able to work but finds no job (Alshammari, 2005) to work because of disability, person old age if the person is unable

Or sickness this is not included in unemployment (obeid, 1997)

There is a gap between the economic activity and man power (Saleh, 1992) Unemployment is being unable to get the goals of any work of the man (www.mady.19.nireblog.com).

Unemployment as a general concept is that a person has the ability and desire to work, looking for it but can't find a work. It is increasing number of the capable people of work while having a real shortage in job opportunities. In Islamic religion unemployment is defined as the disability of earning money as being a child, female, elderly, sick (self disability) or not self disability as being engaged in studying, worshiping without working while having a family which is really forbidden and rejected .

All religious opinions agreed on the loss of the sons' right in having allowance from father if he is able to work because the disable is the one who can't earn his money in the different legal ways. Other sayings about this is that disability is due to very young age, being a female, body disabilities, old age, sickness and not having inherited money for basic needs or not being cared about by rich relatives. If the person's conditions related to one of these, he has the right to take from Zakaat. In addition such poor persons are looked after by the state, which pays for their expenses, clothing medication and their funerals, as well?

\subsection{Kinds of Unemployment (Hasan, 2008)}

1) Fricative unemployment

It is when one part of economy goes towards progress and the other goes towards getting down which leads to demanding special jobs and works.

2) Hierarical Unemployment

It is the change in the ways of production by having new technology to replace the man power.

3) Seasonal unemployment

This is resulted from the setback of economic and weather conditions in some seasons which lead to an inactive work.

4) Cynical unemployment

It includes all sectors of economic activity which resulted from some conditions as wars, general inactive economy.

\section{5) Disguised unemployment}

It is the increasing of workers in the institution in which each one has a sub work does not offer him his basic needs.

The man is the first in economy, so each economic progress depends on man's academic qualification to contribute effectively in development of the community. The unemployment underestimates the value of the individual as an economic resource. The unemployees are converted in to lost energies which affect the economy badly; In addition, they will be an extra burden on the national economy because of the lack of wages for a serious work to deserve such salaries.

The general rights and freedom are not enough to judge the democracy of the political, economic and social systems because the effect of unemployment might shake such systems badly which embarrassed many governments such as the problem of Bedouin in Kuwait.

Unemployment leads the individual to be exposed to lots of no psychological and social harmony. In addition most of unemployees have psychological disorder in their characters they are also unhappy, unsatisfied, disable and unqualified which affect their psychological health badly. The unemployees might be affected by the following psychological disorder.

Depression: Unemployees are highly exposed to be depressed which makes them isolate from others and look for alternative means to take him away from his painful life such as taking drugs and committing suicide.

Low self- esteem: working string strengthens thins the social ties among people and increases the responsibility; whereas employment drives individuals away to disability, boring un satisfaction which leads to low self- esteem and respect 
The isolation and the bad psychology the unemployess have causing lots of diseases such as hypertension ad high blood cholesterol which lead to heart diseases and strokes, in addition to the malnutrition and acquiring un healthy nutrition habits.

\subsection{Related Studies}

Al Dabe (1989) conducted an empirical study about unemployment and the problems of the graduate students from technical school diploma degree and $\mathrm{BC}$ degree in the rural areas and in the city as well. The participants were (800) graduates. The findings showed that the unemployment causes psychological and social problems for the single ones more than the married leading to anxiety, nervousness, being lost, frustration, isolation and depression. The relation between the unemployment and the social and psychological problems was more positive with the university degree participants than those of diploma degree. There were no statistically significant differences of the effect of unemployment on the unemployed attributed to the place of residence the findings also indicated that the health problems were really prominent for the unemployed, followed by the psychological problems.

Anthony \& Marika (1991) conducted a study about the psychological and functional effect of the unemployment on a sample of males' females. It aimed basically to compare between three groups satisfied employee, unsatisfied employee and an unemployed in the psychological and functional effect of the unemployment on those three groups. The sample consisted of (554) male and female participants of the age of 22-23 delivered in these three groups. The self -esteem measurement and the discipline measurement were used The findings indicated that the unsatisfied employees showed psychological comfort less them the satisfied employee In addition, the findings showed that the Unemployment for males was worse than the unsatisfied job and the opposite was for females The unsatisfied job was worse than the unemployment. The findings showed that the social and psychological effect was clear in the life of The unemployed male and female life.

Al Outum (1991) conducted another study about the unemployment in Jordan: its reasons and characteristics in the eighties .The sample consisted of (2379) classified unemployed persons. The findings show that Jordan suffered from unemployment in the last decades in (1948 \& 1967) after the war, whereas the percentage of the unemployment decreases in the middle of seventies The number of unemployment was (60.000) in 1988) in a percentage of (9\%). The highest rates unemployment were (14\%) in the period between (1970-1972) according to the survey of nutrition, health, fertility ,man power and poverty in (1960) The finding also showed no acceptance of some jobs by the Jordanians to be done by the abroad workers the percentage of

Unemployed d females was (4\%) in (1980) and (14\%) in (1987). Al Zerqa governorate has a percentage of unemployed persons which was (18\%) followed by Amman and Al Balqa governorates In the southern area of Jordan the unemployed persons were really in need for help more than any other areas The percentage of the single ones was $(21 \%)$.

Tony (1994) conducted a study about the psychological health of the unemployed employees and the graduates. The study aimed to know the relation between the job status (having a Job, with no jobs and the social adaption with psychological health with the new graduates. The sample was (181) new graduates, (88) employees and (93) unemployees. A questionnaire of the ability for problem solving, discipline measurement and job satisfaction measurement was used. The findings showed that employees. grades were higher in sensitiveness towards others and being patient more than the unemployees The findings also indicated that a high percentage of them was not in the job ,they desired and got lower grades on the measurement of job satisfaction There was also a positive method for the unemployees graduates towards problem solving and higher motivation for achievement They also had better perception for social support as they were sharing in structural entertainment actives more than their employee colleagues. The data assured the hypothesis of the graduates are more capable of adapting with unemployment and job choice does not get along with the expectations or ambitions In addition ,the job might have an effect in the psychological confusion without preparing those graduates to be more effective in doing the jobs.

Ab Saleem (1997) conducted also an analytical study about the-unemployment problem as having an effect on the psychological status of the unemployed and as having the feeling of frustration and lack of self- confidence. This feeling is increased as the period of unemployment in - creases. Its effect on the married ones as being responsible of a family is more than those single unemployed ones which let those married accept any job with fewer wage and even might not suit their educational level.

Abdel Haleem (1997) conducted a field study about the unemployment in Al Mafraq governorate where the sample was (120) job takers and (200) persons looking for jobs. The study summed up that the unemployment is one reason for crime and deviation in the community where prevention from the needs of life reflected 
negatively on the

psychology and the behavior of the unemployed It was also mentioned in this study that the foreigner workers represent a reason for unemployment restricting the use of the Jordanian national power work and increasing the problem of unemployment in its different features and shapes.

A study by Kuwait university (1999) was entitled " The Kuwaiti Youth-Problems "aimed to shed light on the Kuwaiti youth social, economic, educational, psychological and cultural problems and to identify the much more common problems among the participants in order to come up with recommendations to the legislative and executive authority for putting the suitable remedial plans. The sample consisted of (376) male and female students in Al Kuwait university and the, general training

Board for learning. The findings indicated that the problem of not providing the suitable work for the graduates which come in the second rank reflected the size of the unemployment and the difficulty in getting a suitable job for their specializations, in addition to the problem of personal contacts .Such problems caused anxiety about their future work. The problem the disability of the state in investing those youth is in work domains, debts and having no private university representing prominent educational problems .

A study by youth research and studies center (2006) entitled "youth reality and most important needs and attitudes towards their basic issues". aimed to know the youth reality and their needs and attitudes to wards the basic issues. The sample consisted of (9350) young males and females were within (5000) families .The findings indicated that those young people suffered from a number difficulties in marriage, such as low wages, lack of work chances, housing, high marriage expenses and the consent of the families which all lead to bachelorhood phenomenon among the youth They also suffered from psychological ,neurological , and emotional problems with others and in decision marking, as well. In addition, they feared from exam failure and other family problems, such as insufficient family income, small and crowded housing, continuous parents problems, discriminations between brothers and sisters, the fathers involvement in personal issues, fathers bad treatment, the mothers involvement in personal issues ,bad treatment, the mothers involvement $\mathrm{n}$ personal issues, bad treatment of eldest brothers and bad treatment of the mother.

Karl \& Tian (1999) conducted a study about prediction of researching-for work and the psychological health for the unemployed in Australia aimed at identifying the differences between a group of unemployed and employees according to the variables of psychological health, self -competence and commitment to job . The instruments used in the study self confidence measurement, the questionnaire about the general

Health and the measurement of job commitment. The sample consisted of (238) individuals (118) unemployed and (120) employees .The findings showed that the commitment of searching for work is considered an indication for getting the job. In addition the self competency and search commitment indicated that the unemployed individuals who have strong desire for work are less patient in suffering from low self esteem. The findings also indicated that the employed individuals who do not have job commitment were not in the job they prefer.

Al Ghazawi (2008) conducted another study about the effect of unemployment on the political stability aimed to know the effect of unemployment indications on the indications of political stability. The hypotheses of the study indicated that there was a relation between the unemployment and the indications of political stability. In other words, when the rates of unemployment increase, the political stability in Jordan goes down and vice versa. The findings showed no statistically significant relation between the variables of the study. In other words, the unemployment indications in Jordan do not influence the indications of political stability. The findings also indicated statistically significant relation between the unemployment in the governorate and the indications of political stability, although such governorates have high density of population and high level of unemployment. The researcher used the poverty average in Jordan as a medium factor between the indications of unemployment and the indications of political stability. But the statistical analysis showed no relation between the poverty indications in Jordan and the indications of unemployment and between the poverty indications and the political stability in Jordan.

\subsection{What Makes This Study More Significant than the Related Studies?}

The study focused on clarifying the effects resulted from the unemployment and how it caused social, psychological and security problems for the youth. This study is exclusively for the unemployment youth in the Jordanian community it was in agreement with the study of youth research and studies center (2006) in the anxiety, stress and depression for those unemployed individuals for not having a special work for them. Kuwait University (1999) in shedding light on the youth problems resulted from the unemployment. It got along also 
with the study of Al Dabe, (1989) in the psychological and social problems resulted from the unemployment On the other hand, this study was not in agreement with other studies in the sample of the study that included the unemployed individuals only, whereas the study of Tony (1994) was conducted to clarify relation between the social adaption and the new status of the graduates. In addition, the study of Al Ghazawi (2008) studied the effect of unemployment on the political stability with the community apart from dealing with the problem of unemployment and its effect on the youth .As or this study, it assured the existence of unemployment and its effect in causing different social and psychological diseases in the community Whereas the study of Al Outum (1991) assured the existence of unemployment and the suffering of Jordan as a real problem. This study did not get along with most studies in focusing on the social roles the unemployed individuals have according to different ages and the ability of doing the work.

\section{Methods and Procedures}

In this chapter there is a description for the population of the study, the instrument used for data collection, validity and reliability. In addition, there is also a description for the procedures of the study and the statistical treatment used for answering the questions of the study.

The researchers used the analytical descriptive method to conduct this study:

\section{The population}

The population of the study consisted of the youth who suffer from unemployment from males and females in different ages in Ajloun governorate.

\section{The Sample}

The sample of the study was randomly chosen from the unemployees. It consisted of (350) young males and females.

The distribution of the sample is in Table 1.

The distribution of the sample According to the Demographic Variables

Table 1. Distribution of the sample according to the demographic variables

\begin{tabular}{llll}
\hline Variable & Categories & Frequency & Percentage \\
\hline Sex & Male & 140 & $\% 40$ \\
& Female & 210 & $\% 60$ \\
Education & Educated & 217 & $\% 62$ \\
& Non-educated & 133 & $\% 38$ \\
Age & Less than 20 & 63 & $\% 18$ \\
& $30-21$ & 196 & $\% 56$ \\
& more then 31 & 91 & $\% 26$ \\
\hline
\end{tabular}

The researchers used the survey method by making question to cover the areas of the questionnaire. The questionnaire was delivered to a number of young males and females to know the effect of unemployment on the youth.

After reviewing the related studies that related to the topic of this study, the researchers developed a questionnaire to investigate the effect of unemployment on the youth from the perspective of the unemployees themselves. The items of the questionnaire were 21 .

To verify the validity of the study, a jury of specialists in social service judged the instrument of the study. All their comments were taken into consideration.

The values of reliability for the domains of the study according to Cornbach Alpha is shown in Table (2)

Table 2. Reliability values of Cornbach Alpha for the domains of the study

\begin{tabular}{clc}
\hline No & Domain & Validity \\
\hline 1 & The effect of unemployment on the social problems the youth face. & 0.87 \\
2 & The effect of unemployment on the psychological problems the youth face. & 0.84 \\
3 & The effect of unemployment on the youth role. & 0.88 \\
Total & & 0.85 \\
\hline
\end{tabular}


The finding of the study showed a rise in the percentage of reliability value, which indicated a big harmony between the item of each domain and the items of the instrument as a whole which is acceptable for academic research purposes. After verifying the validity of the instrument of the study and identifying the sample, the questionnaire was delivered to the participants after explaining its objectives. The participants of the study were asked to answer the questionnaire accurately and subjectively.

The researchers assured the participants that their answers are secretly treated and used only for academic research purposes. The gradual level of the answer for each item is according to Likert measurement. It is identified as follows: strongly agree (5), agree (4), neutral (3), disagree (2), strongly disagree (1) only one degree. The use of the measurement for the findings was divided into (high, medium, low) according to the categories of the instrument which are four: (1-1.99),

(2- 2.99), (3-3.99) and (4-5). Those categories are divided on the five alternatives which represent (strongly agree, agree, neutral, disagree, and strongly disagree) in a mathematical way $(45=0,8)$ so the three levels are: low degree (1- less than 2.6) medium degree (2.6- less than 3.4) and the high degree (4.3- 5). This division is clarified as follows:

$$
\begin{gathered}
1+(0.8+0.8) 2060 \\
206+(0.8)=3040 \\
304+(0.8+0.8)=.5
\end{gathered}
$$

Therefore, the levels are as follows:

From 1- less than 304 medium degree

$304-5$ high degrees

To answer the questions of the study and to achieve its purposes, the following statistical procedures are is used:

1) For answering the questions one, two and three, the means and the standard deviations are done.

2) For answering the fourth question to find the effect of sex and education, T-Test was used for two independent samples and one.

Way ANOVA Test was used.

3) For getting the reliability of the instrument Cornbach Alpha was used.

4) The frequencies and percentages were done to identify the sample.

To answer the first question which implies "What is the effect of unemployment on the social problems which the youth face?" the mean scores and standard deviations for the answers of the individuals of the sample of the study related to the first domain, were made. The results were as follows.

\begin{tabular}{|c|c|c|c|c|c|}
\hline No. & Items & means & $\begin{array}{c}\text { St. } \\
\text { deviation }\end{array}$ & Rank & $\begin{array}{c}\text { Estimation } \\
\text { degree }\end{array}$ \\
\hline 8 & Late marriage because of having no job. & 3.54 & 1.46 & 1 & high \\
\hline 7 & Acquiring rejected social habits like stealing and anger. & 3.28 & 1.31 & 2 & Med \\
\hline 11 & $\begin{array}{l}\text { The collapsing down of social relations between the } \\
\text { youth and their families. }\end{array}$ & 2.96 & 1.52 & 3 & Med \\
\hline 2 & $\begin{array}{l}\text { The bad influence of social relations between the youth } \\
\text { and the community. }\end{array}$ & 2.88 & 1.3 & 4 & Med \\
\hline 6 & Doing illegal works to get funding and money. & 2.62 & 1.31 & 5 & Med \\
\hline 3 & $\begin{array}{l}\text { The feeling of not being layal of the unemployees to } \\
\text { their community. }\end{array}$ & 2.40 & 1.31 & 6 & Low \\
\hline 4 & $\begin{array}{l}\text { The weakness of national motivation for the } \\
\text { unemployees }\end{array}$ & 2.04 & 1.19 & 7 & Low \\
\hline 5 & $\begin{array}{l}\text { The weakness of national motivation for the } \\
\text { unemployees }\end{array}$ & 1.98 & 1.17 & 8 & Low \\
\hline Total & & 2.71 & 0.58 & & Med \\
\hline
\end{tabular}

Table 3. Means and standard deviation for the answers of the sample on the items that measure the effect of unemployment on the social problem that the youth face 
It is clear from the Table (3) that the means for the answer of the sample were medium. The total mean was (2.71) and the standard deviation was (0.58).

Table (3) showed that the item (8) which implies "late marriage because of having no job" came in the first rank. It's mean was 3.54 Item (7) which implies "acquiring rejected social habits like stealing and anger" came in the second rank in a mean of (3.280). In the third rank there was item (4) which implies "the weakness of religious motivation for the unemployees". Its mean was (2.04). Item (5) came in the last rank. It implies "the weakness of national motivation for the unemployees" which has a mean score of (1.98)

To answer the second question which implies "what is the most important effect of unemployment on the psychological problems that the youth face?" The means and standard deviations for the answers of the participants were done the results are shown in Table (4).

Table 4. Means and standard deviations for the answers of participants the items that measure the effect of unemployment on the psychological problems they face

\begin{tabular}{|c|c|c|c|c|c|}
\hline No & Items & Means & $\begin{array}{c}\text { St. } \\
\text { deviation }\end{array}$ & Rank & $\begin{array}{c}\text { Estimation } \\
\text { degree }\end{array}$ \\
\hline 11 & $\begin{array}{l}\text { Feeling inferior in the community comparing with the } \\
\text { employees }\end{array}$ & 3.84 & 1.8 & 1 & high \\
\hline 13 & Feeling of anxiety & 3.68 & 0.82 & 2 & High \\
\hline 10 & Feeling of frustration & 3.62 & 1.10 & 3 & High \\
\hline 12 & Feeling shy & 3.42 & 1.11 & 4 & High \\
\hline 14 & $\begin{array}{l}\text { Acquiring Psychological habits as hypocrisy and } \\
\text { showing off. }\end{array}$ & 3.42 & 1.13 & 5 & High \\
\hline 9 & Unemployees feel lazy with no desire to work & 3.32 & 22.1 & 6 & med \\
\hline 15 & Showing carelessness to their community & 3.20 & 1.1 & 7 & med \\
\hline \multirow[t]{2}{*}{16} & Violating the customs and traditions of the community & 2.86 & 1.18 & 8 & med \\
\hline & Total & 3.42 & 0.66 & & High \\
\hline
\end{tabular}

It is clear frame Table (4) that the means were high and medium for the items according to the answers of the participants The total mean was (3.42) and the total standard deviation was (0.66).Table (4) showed that item (11) which implies" feeling inferior in the community comparing with the employees" came in the first rank Its mean score was (3.84), whereas item (13) that implies" feeling of anxiety" took the second rank in mean score of (3.68).Item (15) was in rank three. It implies" showing carelessness to their community" Its mean was (3.20) the last rank was for item (16) that implies "violating the customs and the traditions of the community". Its mean was (2.86).

To answer the third question that implies "what of the effect of unemployment a role of the youth"? The means and standard deviations were done for the answers of the participants the results are shown in Table (5).

Table 5. Means and standard deviations for the answers of the participants for the items that measures thy effect of unemployment on the role of the youth

\begin{tabular}{llccccc}
\hline No & Items & means & $\begin{array}{c}\text { St } \\
\text { deviations }\end{array}$ & $\begin{array}{c}\text { Rank } \\
\text { Estimation } \\
\text { degree }\end{array}$ \\
\hline 21 & $\begin{array}{l}\text { Weakens of national and security role for youth in } \\
\text { protecting the community }\end{array}$ & 3.94 & 0.69 & 1 & High \\
18 & $\begin{array}{l}\text { Unactive role of youth in the development of the } \\
\text { community }\end{array}$ \\
19 & $\begin{array}{l}\text { Disorder of social life for the youth in the community } \\
\text { The youth's social diseases that affect their role in the } \\
\text { social life. }\end{array}$ & 32.38 & 1.19 & 2 & High \\
20 & $\begin{array}{l}\text { Nonnative role of the youth in economic of the } \\
\text { community } \\
\text { Total }\end{array}$
\end{tabular}


It is clear from Table 5 that the means were high according to the answers of the participants. The total mean was (3.49), whereas the total standard deviation was (0.84) .Table (5) showed that item (210) which implies "weakness of national a security role of the youth in protecting the community "came in the first rank having .a mean score of (3.94), whereas item (18) that implies "inactive role of the youth in the development of the community "came in the second rank having a mean score of 3.68. In the third rank there was item (22) which implies "the social diseases of the youth that affect their role in the social life" .It's mean score was (3. 38). Item (20) came in the last rank .It implies inactive sharing of youth in the economic development of the community." Its mean score was (2.92).

\section{Statistical References}

\subsection{Sex}

T- Test was used for two independent samples. The results are shown in Table (6).

Table 6. Means and standard deviations and t-value for the differences test among the answers of the participants Attributed to sex variable

\begin{tabular}{|c|c|c|c|c|c|}
\hline Domain & Sex & Means & $\begin{array}{c}\text { St. } \\
\text { deviation }\end{array}$ & T-value & $\begin{array}{l}\text { Sig. } \\
\text { reference }\end{array}$ \\
\hline \multirow{2}{*}{$\begin{array}{l}\text { The effect of unemployment on problems that the } \\
\text { youth face }\end{array}$} & Male & 3.92 & 0.65 & 0.014 & 0.912 \\
\hline & Female & 4.36 & 0.56 & & \\
\hline \multirow{2}{*}{$\begin{array}{l}\text { The effect of unemployment on the psychological } \\
\text { problems of the youth }\end{array}$} & Male & 4.00 & 0.62 & 0.098 & 0.301 \\
\hline & Female & 4.26 & 0.49 & & \\
\hline \multirow[t]{2}{*}{ The effect of unemployment on the role of the youth. } & Male & 3.94 & 0.84 & 0.098 & 0.451 \\
\hline & Female & 3.91 & 0.86 & 0.190 & \\
\hline
\end{tabular}

4.2 Ages

One way ANOVA analysis was done. The results are shown in Table (7).

Table 7. One way ANOVA analysis for the effect of age variable for the answers of the age participants

\begin{tabular}{llllll}
\hline Domain & $\begin{array}{l}\text { Source of } \\
\text { variance }\end{array}$ & $\begin{array}{l}\text { Total of } \\
\text { squares }\end{array}$ & $\begin{array}{l}\text { Means of } \\
\text { squares }\end{array}$ & F-value & $\begin{array}{l}\text { Sig. } \\
\text { reference }\end{array}$ \\
\hline $\begin{array}{l}\text { The effect of unemployment on the } \\
\text { social problems of the youth }\end{array}$ & Between groups & 1.525 & 0.762 & 1.976 & 0.150 \\
& Within groups & 18.136 & 0.386 & & \\
& Total & 19.660 & 1.95 & 0.617 & 0.544 \\
The effect of psychological problems & Between groups & 0.391 & 0.317 & & \\
on the youth & Within groups & 14.881 & & & \\
& Total & 15.272 & & & \\
The effect of unemployment on the & Between groups & 1.951 & 0.650 & 0.802 & 0.499 \\
role of the youth & Within groups & 36.491 & 0.811 & & \\
& Total & 38.441 & & & \\
\hline
\end{tabular}

Table (7) shows the differences among the answers of participants according to age differences .It indicated no statistically significant differences at the level $(\propto=0.05)$

This indicated no statistically significant differences among the answers of the participants attributed to the variable of age.

\section{The Findings of the Study}

The study came up with the following findings:

1) As for the effect of unemployment on social problems of the youth, the study showed that the late age of marriage is the real problem resulted from the unemployment. In addition, the unemployment leads to empty time which causes acquiring bad habits as stealing and other things.

2) The effect of unemployment on the psychology the study indicated the feeling of inferiority is a real feeling resulted from unemployment especially when the unemployed compares him with those who have jobs. In 
addition, the feeling of anxiety and frustration overwhelming all those who have no work.

3) As for the role of the youth, the study showed that the unemployment causes social diseases and affects the role of the youth in the social life. In addition, it drives them to disordering which affect their abilities to have their real roles in the community.

4) There were no statistically significant differences attributed to demographic variables according to the answers of the participants.

\section{Recommendations}

1) Institutions and colleges should find job opportunities for their graduates in the private sector and in businessmen sector.

2) The government should encourage towards the work that their efforts could be invested in such as free business and other works.

3) Funding the social credit for the graduates who suffer from unemployment but having thoughts for successful projects.

4) Cooperation between the state and the businessmen to encourage the investment to create new job opportunities that reduce the percentage of the unemployment that the communities have.

\section{References}

Abdel Haleem, A. J. (1997). Unemployment in Mafraq Governorate Majalat Abhath AL yarmouk. Deanship of Academic Research and Higher Studies, 13(2), 227.

Abu Saleem, W. (1997). The problem of Unemployment: Reality and Solutions. Yarmouk Magazine.

Al Dabu Abdel Rauf. (1989). Unemployment and the Youth Prophems: A Field study on the Technical colleges and universities in rural reas and HN cities ALESKANDARIYA. Dar AL Mrifah al jamyah, 5.

Al Ghazawi Ola Basheer. (2008). The Effect of Unemployment on Political Stability in Jordan Unpublished M. A. thesis yarmouk university Irbid: Jordan.

Al Outum, E. S. (1991). Unemployment in Jordan. Reasons and characteristics in the Eighties. Unpublished M.P. Thesis: University of Jordan: Amman, 9-10.

AL Shammari Saleh. (2005). Security and Technician. Al Riyadh journal Thursday 18 Shawwal 1426H.-10th Nov .On (1365).

Ali, M. I. T., Mustafa, S., \& Khouri, L. (1990). Study for Expansion Female Employment In Jordan. Report prepared by the Royal Scientific Society Economic Research center, Amman, Jordan.

Anthony, W., \& Marika, T. (1991).The psychological Impact of Unemployment and Unsatisfactory Outcome Employment men and British. Journal of Psychology, 82, 473-488.

Aroui, F. (1992, May). In D. Neff, J. Wall, L. Weber, \& W. Reynolds (Eds.), an assessment of Vocational and technical Education in Jordan, Amman. Ncerd: Publication series no. 13.

Cantor, D., \& Land, K. C. (1985). Unemployment and Crime Rates in the post -World War II United States: A Theoretical and Empirical Analysis. American Sociological Review, 50(3), 317-332. http://dx.doi.org/10.2307/2095542

Center of Youth Studies and Research. (2006). Youth Reality Needs and Attitudes Towards .Their Basic Issues. Youth union of Rebellion, Damascus.

Crutchfield, R. D. (1989). Labor satisfaction and Violent Crime. Social, 489-512.

Hassan khalafl Badawi Khalaf. (2008). Unemployment in Egypt an Introduction to the Administration of the ways project leading to Higher education within the demands of the certificate of attending a Training program in summer.

Karl, W., \& Tina, O. (1999). Predicting Job Seeking Frequency and Psychological Well-being in the $\begin{array}{lllll}\text { Unemployed. Journal of Employment } & \text { counseling, } & 36, & 67-81 .\end{array}$ http://dx.doi.org/10.1002/j.2161-1920.1999.tb01010.x

Tony, C. (1994). The Psychological Health of Employed and Employed recent Graduates as a Function of their cognitive appraisal and coping. Counseling Psychology Quarterly, 7, 385-399. http://dx.doi.org/10.1080/09515079408254161 